https://helda.helsinki.fi

The Contradiction (Russell and Grelling), and the flaw in it

\author{
Maury, Andre
}

2020-02-25

Maury , A 2020 , ' The Contradiction (Russell and Grelling), and the flaw in it ' , Open

Science Framework Preprints . https://doi.org/10.31219/osf.io/djgyv

http://hdl.handle.net/10138/312467

https://doi.org/10.31219/osf.io/djgyv

submittedVersion

Downloaded from Helda, University of Helsinki institutional repository.

This is an electronic reprint of the original article.

This reprint may differ from the original in pagination and typographic detail.

Please cite the original version. 
André Maury, University of Helsinki (andre.maury@helsinki.fi)

Abstract

In the Principles of Mathematics Russell presents a contradiction which arises from his use of the predicate "not predicable of itself". Russell blames the predicate for the contradiction. However, it arises because he makes a mistake in not distinguishing properly between the predicate and its relation to itself. The paradox of classes follows from a disregard of the difference between a class and its relation to itself. Grelling puts the contradiction in terms of "heterological", and repeats Russell's mistake, However, Grelling's stress on meaning gives us a clue to resolving these contradictions. The points made are not discussed in the vast literature on Russell and Grelling.

The Contradiction (Russell and Grelling), and the flaw in it.

In a letter to Frege Russell states a contradiction which he has reached, without giving his argument.(1) Frege did not ask for the argument. He should have. There is a logical flaw in the argument, due to the fact that Russell does not get right the meaning of the central phrase "not predicable of itself".

Russell regarded the argument involving that phrase, in \#78 of The Principles of Mathematics, as important, or at least surprising,and in the book he applies it to classconcepts, relations and also, famously, to classes.(2)

But his attitude to it is ambivalent. He admits that something goes wrong, because of the contradiction. But he does not care to find out what goes wrong. That will be attempted here.

Russell's argument will be compared with Grelling's version of it. Grelling also thinks something is wrong, but he blames himself for not being able to point the eventual failure of meaning (somewhere). This is not in Russell. Hopefully the comparison is clarifying.

In view of the importance of the argument for Russell it is surprising that it is not discussed in the literature. Its off-shot, the paradox of classes, seems to be accepted just like that.

In a recent, thick, volume of articles A Hundred Years of Russell's Paradox the argument is not even mentioned. It should be. The paradox is after all an application of the argument.

Grelling's paradox gets more attention, but the connection with Russell's argument is not stressed (usually not even mentioned). The flaw is there too.

The issue arises as follows.

1.The setting. 
The materials in the argument are scant, the phrase "not predicable of itself" and a rule (RP), used but not stated Yet Russell manages to set up an argument which is almost unintelligible, mainly because RP is not mentioned.

Nevertheless the pattern is simple, and it depends centrally on the rule RP, namely that if a predicate is "predicable of itself" it belongs to the class it defines. (In contrast to Grelling, Russell gives no criterion for this "belonging".)

Russell gets his contradiction by assuming that the predicate "not predicable of itself" both defines the class and belongs to it, i.e.it is, after all, predicable of itself. It is both predicable and not predicable of itself, then.

The key passage in Russell's brief introduction to the argument is this:

"It is natural to suppose that ((the predicates which are not predicable of themselves)) form a class having a defining predicate. But if so, let us examine whether this defining predicate belongs to the class or not".

Either way, we land in a contradiction, Russell holds.

The contradiction is resolved by noting that the defining predicate of the class and the predicate which belongs to the class are different predicates, though the phrase is the same.

As a member of the class the predicate means a relation, right. The defining predicate of the class means, however, that any member displays a certain relation to itself, a different matter.

Russell's examination proceeds as follows (and his neglect of the difference mentioned has quite far-reaching consequences),

\section{The argument.}

First statement:

"If it belongs to the class, it is not predicable of itself, for that is the characteristic property of the class. But if it is not predicable of itself, then it does not belong to the class whose defining predicate it is, which is contrary to the hypothesis."

and also:

"(If) it does not belong to the class whose defining property it is, then it is not predicable of itself, i.e. it is one of those predicates that are not predicable of themselves, and therefore it does belong to the class whose defining predicate it is -again contrary to the hypothesis.(italics added)

Here Russell does not state the central premiss, namely that a predicate which belongs to the class it defines is predicable of itself (RP). No more is needed for the contradiction, and no more is needed for seeing that RP, which is allright in itself, does not apply in the case at. hand. Let us look at this point first. 
RP does not apply simply because "it", the predicate, does not, as a member of the relevant class, define that class. The class is defined by that relation to itself which any member of the class is to display (and "not predicable of itself" is no exception).

As a member the predicate means a relation, right, but it does not, as a member, mean that relation which qualifies it as a member of that class, namely that it stands in that relation to itself (since it does not, as a member, mention itself)..

In Russell's explicit argument the central phrase is used in two ways, indeed two incompatible ways.

First it works for the assumed membership, then against that membership (as if the phrase is to blame for the confusion). Russell thinks that the phrase, in the second use, denies that the predicate as such belongs to the assumed class. It does not. It only denies that it has a certain relation to itself (which is why it does qualify as a member in the assumed class)

However, Russell's basic mistake is in his misuse of RP. His disregard of the meaning of "itself" comes too late to make any difference (the damage is already done).

Later in the text, and also in the letter to Frege, only outlines of the argument are given.

\section{Outlines.}

First "an exact statement of the contradiction":

"If $x$ be a predicate, $x$ may or may not be predicable of itself. Let us assume that "notpredicable of oneself" is a predicate. Then to suppose either that this predicate is, or that it is not, predicable of itself, is self-contradictory. The conclusion, in this case, seems obvious:"not-predicable of oneself" is not a predicate." (Principles, p.102)

We are, then, to understand this without argument. Russell assumed that Frege could (again in the letter):

"Let $w$ be the predicate of being a predicate which cannot be predicated of itself. Can $w$ be predicated of itself? From either answer follows its contradictory. We must therefore conclude that $w$ is not a predicate".(3)

Why anything of this should be so is not said. The matter is taken to be self-evident, apparently, Thought out prima vista, as it were, there is a contradiction, though only on the surface.

Russell continues ( leading Frege on):

"Likewise, there is no class (as a whole) of these classes which, as wholes, are not members of themselves. From this I conclude that a definable set does not form a whole." 
Here Russell moves from "not predicable of itself" to "not a member of itself" (smoothly because the connection is, for Russell, close).

Even if the predicate "not a member of itself" defines a very comprehensive class (of classes) it is not that predicate, or property, in virtue of which any member-class is a member.

That property is a result, so to speak, of the relation to itself which any member of the class is to display.

( So the class of lions is not a member of itself, because it is not a lion (not because it is not a member of itself.)

In the case leading up to a "paradox" Russell asks whether the comprehensive class could be a member of "itself". For this we would need a "because", not just the result. However, no such defining property is in sight.

The conclusion that there is no such class does not, then, follow. What follows is that the very question cannot be put.

\section{Meaning.}

Grelling gives the meaning of the relevant predicate a role (in contrast to Russell). Thus Grelling is able to set up a proper criterion for when a predicate is predicable of itself (with the additional benefit that classes are not needed, since RP is not needed).

In setting up his version Grelling relies on Hessenberg, the main reference in Grelling's and Nelson's account of paradoxes in their paper. (4)

Hessenberg's reference is to \#78, but in fact he uses Russell's outline only. The novelty is that he replaces Russell's main notions by "impredicable" and "predicable".

Grelling introduces his version of Hessenberg's formulation by "Russell bemerkt": "Impredicable" is predicable/impredicable, so it is impredicable/not impredicable (Russell would say "predicable", but let that pass).

Grelling follows, but uses the terms "heterological" and "autological".

However, the novelty is that he sets up a criterion for a predicate, or a "word", as he says, being either. He draws on the meaning of the word, and sets up a rule, which is,then,swiftly applied:

"Jedem Wort kommt der Begriff, den es bezcheinet, entweder als Merkmal zu oder nicht. Im ersten Fall nennen wire s autologisch, im zweiten heterologisch. 
"Das Wort "heterologisch" ist nun selbst entweder autologisch oder heterologisch.

Angenommen es sei autologisch, dann kommt inm den Begriff, den es bezeichnet, als Merkmal zu, es ist also heterologisch. Angenommen, es sei heterologisch, dann kommt inn den Begriff, den es bezeichnet, nicht als Merkmal zu, es ist also nicht heterologisch."

This is crisp, elegant and deceptive. You are meant to see the apparent contradiction prima vista. In fact there is no contradiction, only restataments of the rule.

Terminology aside, the rule says that, for instance, "short" is autological: it means short and is short. "Long" is heterological, it means long but is not long.

Applied to "heterological" the rule, then, says that if "heterological" is autological-it is what it means-then it is heterological. Right, assuming that "heterological" means heterological.

And also, then:

If the word is heterological- it is not what it means- then, it is not heterlogical.

These are trivial applications of the rule set up, nothing more. Like Russell he misses the difference between a word, in this case, and its relation to itself.

Grelling, in his turn, knows that something is wrong, and holds that if we could point out a failure of meaning in the argument the paradox would be resolved. Be that as it may, it is enough to point out that it is a logical mistake to conflate a thing with its relation to itself.

Grelling's criterion can, of course, be applied to Russell's predicate of interest, and similarly no contradiction arises. However, it cannot be applied to the cases with classes-a class means nothing.

It is said that Zermelo also came up with Russell's paradox. It would be nice to take part of his argument. (5)

Notes

1.Russell's letter to Frege, in Frege, beloiw.

2.The relevant passage introduces \#78 in The Principles of Mathematics: "Among predicates, most of the ordinary instances cannot be predicated of themselves, though,by introducing negative predicates, it will be found that there are just as many instances of predicates which are predicable of themselves. One at least of these, namely predictability, or the property of being a predicate, is not negative: predictability, as is evident, is predicable,i.e. is a predicate of itself. But the most common instances are negative: thus non-humanity is non-human, and so on. The predicates which are not predicable of themselves are, therefore, only a selection from among predicates, and it is natural to suppose that they form a class having a defining predicate. But if so, let us examine whether this defining predicate belongs to the class or not."

3. In the book the paradox is put like this (and we are to understand it): 
"In terms of classes the contradiction appears even more extraordinary. A class may as one be a term of itself as many.....Is it as one a member of itself as many or not? If it is, then it is one of the classes which, as ones, are not members of themselves as many, and vice versa. Thus we must conclude ....that the classes which as ones are not members of themselves as many do not form a class." (p.102)

4. Gerhard Hessenberg, Grundbegriffe (see below), \#97 especially the footnote.

A fuller account of Grelling's argument, and the reception of it, is given in my "Grelling, in his own words" (forthcoming).

5. My thanks are due to Nike Parland, BA, and the participants in various lively seminars.

\section{References}

K. Grelling and L. Nelson, Bemerkungen zu den Paradoxien von Russell und Burali-Forti, Abhandl. D. Friesschen Schule, 1908. Reprinted in Nelson's collected papers, Verlag Felix Meiner, Hamburg, 1974.

Frege, G. Philosophische und Mathematische Correspondence,G.Gabriel,H.Hermews,F.Kambartel,C.Thiel,A.Veraat (edd.)abridged from the German by B.F.McGuinness, Hans Kaal (transl.), The University of Chicago Press, 1980.

Hessenberg, G. Grundbegriffe der Mengenlehre, Vanderhoeck \&Ruprecht, Göttingen 1906.

One Hundred Years of Russell's Paradox, Godehard Link, ed. Walter de Gruyter, Berlin, NY, 2004.

Russell, B., The Principles of Mathematics, Georg Allen \&Unwin, London 1964 (1903, 2nd edition 1937). 